\title{
Improved catalytic combustion of methane using CuO nanobelts with predominantly (001) surfaces
}

\author{
Qingquan Kong ${ }^{1}$, Yichun Yin ${ }^{2}$, Bing Xue ${ }^{3,4}$, Yonggang Jin ${ }^{*}$, Wei Feng ${ }^{1}$, \\ Zhi-Gang Chen ${ }^{6}$, Shi Su${ }^{5}$ and Chenghua Sun ${ }^{*}$
}

\author{
Full Research Paper \\ Address: \\ ${ }^{1}$ School of Mechanical Engineering, Chengdu University, Chengdu \\ 610106, Sichuan, PR China, ${ }^{2}$ School of Chemistry, Faculty of \\ Science, Monash University, VIC 3800 Australia, ${ }^{3} \mathrm{CSIRO}$ Energy, PO \\ Box 883, Kenmore, QLD 4069 Australia, ${ }^{4}$ School of Environment and \\ Resources, Southwest University of Science and Technology, \\ Mianyang 621000, PR China, ${ }^{5}$ CSIRO Energy, 1 Technology Court, \\ Pullenvale QLD 4069, Australia, ${ }^{6}$ Centre for Future Materials, \\ University of Southern Queensland, Springfield QLD 4300, Australia \\ and ${ }^{7}$ Department of Chemistry and Biotechnology, Faculty of Science, \\ Engineering \& Technology, Swinburne University of Technology, \\ Hawthorn, VIC 3122, Australia \\ Email: \\ Yonggang Jin * yonggang.jin@csiro.au; Chenghua Sun * - \\ chenghuasun@swin.edu.au \\ * Corresponding author \\ Keywords: \\ catalytic oxidation; copper oxide; density functional theory; methane \\ Beilstein J. Nanotechnol. 2018, 9, 2526-2532. \\ doi:10.3762/bjnano.9.235 \\ Received: 12 June 2018 \\ Accepted: 10 September 2018 \\ Published: 24 September 2018 \\ Associate Editor: J. J. Schneider \\ (C) 2018 Kong et al.; licensee Beilstein-Institut. \\ License and terms: see end of document.
}

\begin{abstract}
Through computational calculations, $\mathrm{CuO}(001)$ has been identified as an active surface for methane oxidation. Experimental validation with $\mathrm{CuO}$ nanobelts comprised of predominantly (001) surfaces has been performed and it is confirmed that the performance of such nanobelts is much higher than normal nanoparticles and nanowires. First principle calculations further clarified that two-coordinated oxygen plays a key role for methane adsorption and oxidation.
\end{abstract}

\section{Introduction}

Methane $\left(\mathrm{CH}_{4}\right)$, as the main component of natural gas, offers significant environmental advantages over conventional gasoline and diesel [1-3]. However, its thermal combustion is often at a flame temperature up to $\approx 2,000 \mathrm{~K}$ [4], which favours the formation of nitrogen oxide $\left(\mathrm{NO}_{x}\right)$ pollutants. To suppress such reactions, a lower flame temperature is targeted, but this poten- tially results in incomplete combustion with large $\mathrm{CO}$ and unburned hydrocarbon (UHC) emissions [5], which underlines the need to develop high-performance catalysts for $\mathrm{CH}_{4}$ oxidation at low temperature. Except as fuel in natural gas, much of the $\mathrm{CH}_{4}$ that is released is from industrial applications, such as ventilation air methane (VAM) from underground coal mining. 
This is a serious issue because $\mathrm{CH}_{4}$ has severe global warming effects, around 25 times greater than that of carbon dioxide $\left(\mathrm{CO}_{2}\right)$. For a more efficient use of natural gas and to minimize the direct emission of $\mathrm{CH}_{4}$, the catalytic oxidation of $\mathrm{CH}_{4}$ at low temperature has been investigated extensively over the last decades [5-8].

Noble metals have been reported as effective catalysts for the complete oxidation of methane [2,5,9-17], particularly supported Pd nanoparticles [15-17], while the high price and poor thermal stability limit their large scale application. To address this issue, low-cost alternatives, such as transition metal (TM) oxides and various complex structures (e.g., perovskite, spinel and hexaaluminate) have been tested as catalysts for $\mathrm{CH}_{4}$ oxidation. But so far their performance is still much lower than noble metals. An ideal catalyst for $\mathrm{CH}_{4}$ oxidation should have a high capacity to adsorb $\mathrm{CH}_{4}$ (particularly important for $\mathrm{CH}_{4}$ oxidation at low concentration, for example, VAM mitigation), activate the $\mathrm{C}-\mathrm{H}$ bond and split the $\mathrm{O}_{2}$ molecule. However, exposed catalyst surfaces are often highly stable and thus can hardly satisfy all of the above criteria, which explains the poor performance of most metal oxides.

To improve the reactivity of metal oxides, surfaces with high energy (and thus low surface area), namely minority surfaces, may offer new opportunities. Although minority surfaces often diminish quickly during crystal growth due to their low stability, they can be stabilized by controlling the synthesis conditions, as previously demonstrated in the literature [18-20]. In terms of reactivity, minority surfaces have a large amount of lowly coordinated atoms that can be actively involved in surface reactions, including adsorbing $\mathrm{CH}_{4}$ and stabilizing intermediates [7]. Following this strategy, this work explores the catalysis of copper oxide $(\mathrm{CuO})$, a promising catalyst for $\mathrm{CH}_{4}$ oxidation as identified in the literature [8]. Different from these reports, we focus on the performance of the minority surface (001).

\section{Results and Discussion}

Starting with computational calculations, $\mathrm{CuO}$ surfaces with low indexes (including (110), (111), (101), (010), (011) and (001)) have been systematically screened under the scheme of density functional theory. The stability of these surfaces has been reported earlier as $(010)>(011)>(100)>(101)>(110)>$ (001) [21], according to which 001 is the most reactive surface, which is consistent with our work as demonstrated below.

Two indicators, namely the adsorption energy (AE) and dissociation energy (DE, energy change from physical adsorption to dissociative adsorption), are employed for the analysis. The surface models are shown in Figure 1a. Given that the catalysts are exposed to abundant oxygen, $\mathrm{O}$ or $\mathrm{O} / \mathrm{Cu}$-mixed termination is employed in the models. Among them, five are featured with mixed $\mathrm{O} / \mathrm{Cu}$ surface atoms, except $(001)$ which is fully covered by two-coordinated oxygen $\left(\mathrm{O}_{2 \mathrm{c}}\right)$ before it is relaxed. Very recently, $\mathrm{O}_{2 \mathrm{c}}$ has been identified as an active site for $\mathrm{CH}_{4}$ oxidation in the case of $\mathrm{Co}_{3} \mathrm{O}_{4}$ whereby $\mathrm{CuO}(001)$ offers an ideal opportunity to test this hypothesis [22].

The AE and DE are calculated and presented in Figure 1b, with negative $\mathrm{AE}(\mathrm{DE})$ indicating that the adsorption (dissociation) is favorable. Based on the calculated AE, it is found that the physical adsorption of $\mathrm{CH}_{4}$ on (101), (011), (010) and (001) can occur without additional energy input, with an $\mathrm{AE}$ between -0.22 and $-0.86 \mathrm{eV}$. The (001) surface, with $\mathrm{AE}=-0.86 \mathrm{eV}$, has been identified as the surface that offers the strongest adsorption capacity among all these surfaces. For $\mathrm{CH}_{4}$ oxidation, the dissociation to form $\mathrm{CH}_{3}$ and $\mathrm{H}$ is critical and difficult because strong $\mathrm{C}-\mathrm{H}$ bonds need to be broken; therefore, the calculated DE is indicative of the oxidation difficulty. Interestingly, the (001) surface has been identified again as the most reactive surface for $\mathrm{CH}_{4}$ dissociation, with $\mathrm{DE}=-2.16 \mathrm{eV}$, which is much higher than that of the other surfaces. On the basis of the above computational screening, (001) is the optimal surface for $\mathrm{CH}_{4}$ oxidation among these tested surfaces. From
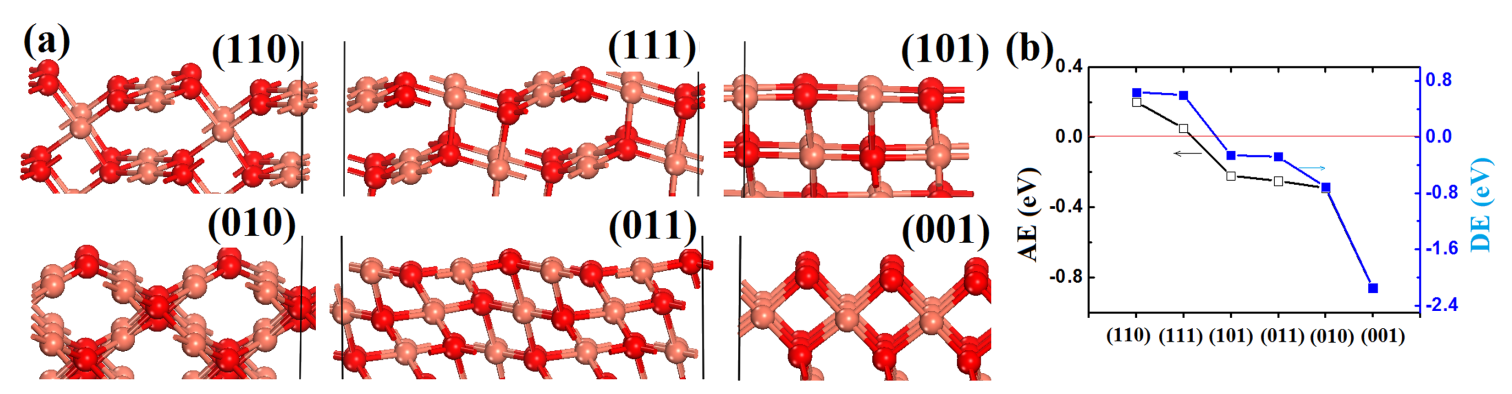

Figure 1: Computational screening. (a) Models for six low-index surfaces (unrelaxed); (b) Calculated values of $A E$ and DE. Cu and $O$ are shown as rose-carmine and red, respectively. 
the analysis of the surface, this is not surprising because (001) is strongly polarized and shows high reactivity due to the high ratio of lowly coordinated oxygen - a feature that has been employed for gas sensing and Li-ion batteries [21].

Now we turn to the experimental validation, starting with the synthesis of $\mathrm{CuO}$ nanowires (NWs) and $\mathrm{CuO}$ nanobelts (NBs) comprised of predominantly (001) surfaces, which is performed based on the method reported by Van Tendeloo et al [23]. For the NWs and NBs synthesized in this work, a high percentage of the surface area can be attributed to (001) surfaces, particularly for the NBs whose (001) surfaces are the predominant surface found, as examined by transmission electron microscopy (TEM). Figure $2 \mathrm{a}, \mathrm{b}$ shows the NWs which have a diameter of $20-100 \mathrm{~nm}$ and length of $1-3 \mu \mathrm{m}$, and Figure $2 \mathrm{c}$ shows the thin NBs, with a width of $200-300 \mathrm{~nm}$ and a length of $\approx 1 \mu \mathrm{m}$. The selected area electron diffraction patterns (SAED), projected from the [1] zone axis of the yellow square area (see the inset in Figure 2c), reveals the monoclinic structure and that the diffraction spots are ascribed to the (110), $(-110)$, and (020) planes. High-resolution TEM images, as shown in Figure 2d, confirm that the exposed surface of the NBs is the (001) facet and the edge is (100). As shown in an early study [21,23], $\mathrm{CuO}$ NWs or NBs having predominantly (001) surfaces can be obtained when $\mathrm{Cu}(\mathrm{OH})_{2}$ is employed as a nanowire precursor for decomposition. The mechanism of shape-reserved transformation from $\mathrm{Cu}(\mathrm{OH})_{2}$ to $\mathrm{CuO}$ has been previously discussed in the literature [24-26].

Prior to the performance tests, the crystal structure of the collected samples was further examined by X-ray diffraction with commercial $\mathrm{CuO}$ nanoparticles (NPs, Aldrich 450812) as a reference for comparison. The NP, NW and NB samples show the similar profiles, confirming that they have the same phase (CuO, space group: $\mathrm{C} 2 / \mathrm{c} 2(15), a=4.685 \AA, b=3.425 \AA$, $c=5.130 \AA$ ), as shown in Figure S1, Supporting Information File 1. However, the NB sample shows a much stronger (002) peak, suggesting a preferred (001) termination. It is also found that the NP, NW and NB samples have a similar surface area of around $1 \mathrm{~m}^{2} / \mathrm{g}$ as measured by the Brunauer-Emmett-Teller (BET) method from $\mathrm{N}_{2}$ adsorption isotherms at $77 \mathrm{~K}$, suggesting that the performance difference presented below does not come from the difference of the surface area.

We now compare the catalytic performance of different $\mathrm{CuO}$ catalysts for $\mathrm{CH}_{4}$ oxidation. We began with catalytic oxidation
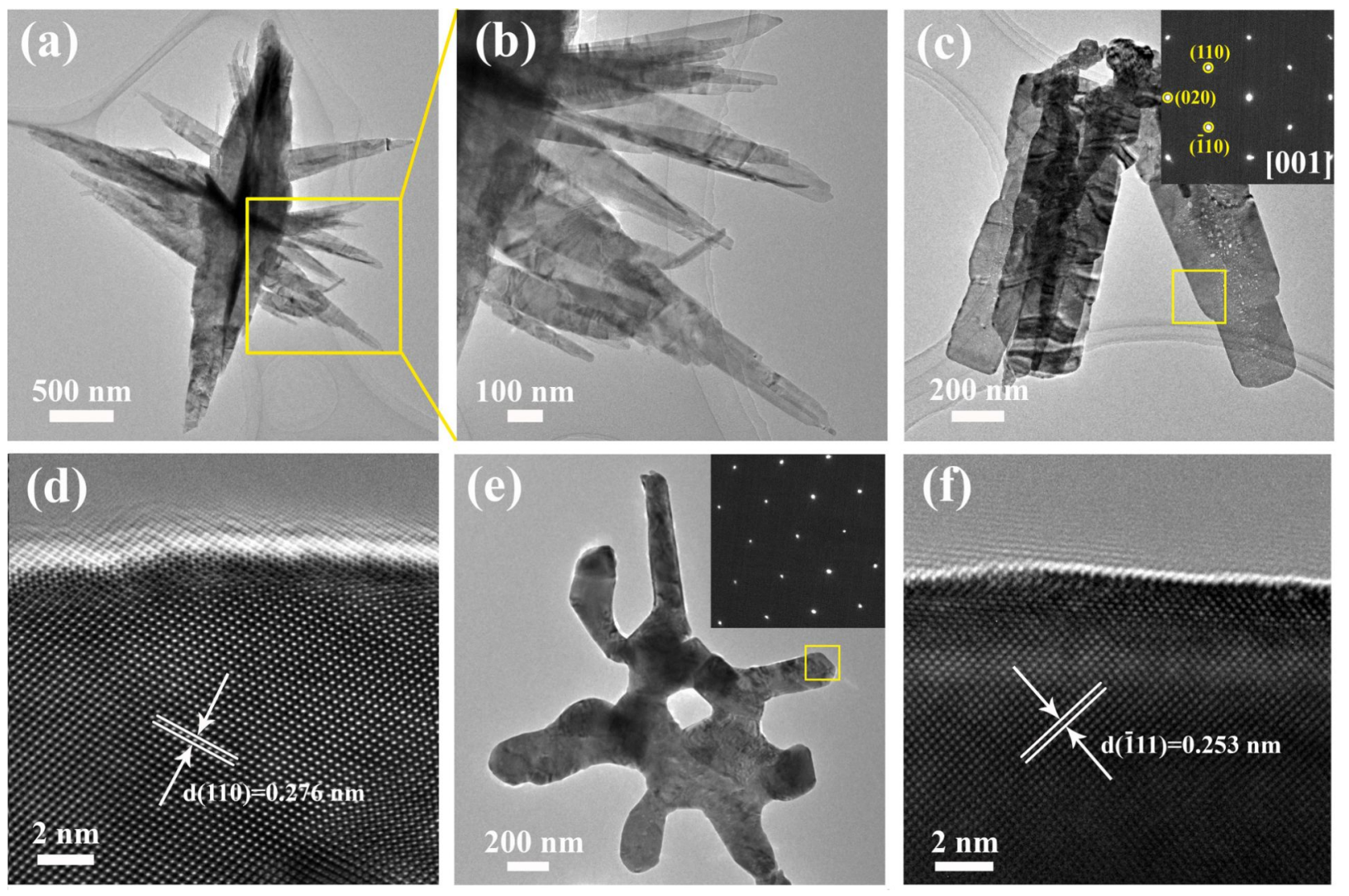

Figure 2: CuO catalyst characterization. (a,b) TEM images of CuO NWs; (c) TEM image of CuO NBs (inset is the SAED pattern of the selected yellow square area); (d) HRTEM along the [1] direction; (e,f) TEM images of a CuO nanobelt after catalysis tests at $650^{\circ} \mathrm{C}$. 
tests, starting from $150{ }^{\circ} \mathrm{C}$ up to the maximum testing temperature, $T_{\max }=850^{\circ} \mathrm{C}$. After the first cycle of the test (denoted as $\mathrm{C} 1$ ), the catalytic bed was cooled down from 850 to $150{ }^{\circ} \mathrm{C}$ followed by the second test cycle (C2). Figure 3 a shows the C1-performance of the NP, NW and NB samples where the oxidation activity follows the order: NBs $>$ NWs $>$ NPs. It is particularly notable that the NB performance is even close to that of $1 \% \mathrm{Pd}$ loaded on $\mathrm{Co}_{3} \mathrm{O}_{4}$ [27], which itself shows excellent catalytic capacity. Supermolecular $\mathrm{Pd} @ \mathrm{CeO}_{2}$ core-shell structures can offer exceptionally high performance for methane oxidation, achieving complete conversion even below $400{ }^{\circ} \mathrm{C}$ [6]. Different from Pd catalysts, $\mathrm{CuO}$ NBs, as a low-cost metal oxide material, do not have to be loaded on a support and do not use additional dispersion agents, and are thus a more effective catalyst per volume and weight when assembled on the reactor.

The aggregation of catalyst nanoparticles upon high-temperature calcination is a typical issue for $\mathrm{CH}_{4}$ oxidation, which was also observed in our experiments. All three $\mathrm{CuO}$ catalysts demonstrated poor thermal stability leading to significantly deteriorated catalytic performance in $\mathrm{C} 2$ compared to that in $\mathrm{C} 1$ when the combustion temperature was as high as $850{ }^{\circ} \mathrm{C}$. Therefore, $\mathrm{CH}_{4}$ oxidation catalyzed by NBs at lower temperature $\left(600^{\circ} \mathrm{C}\right)$ was tested, and the results are shown in Figure $3 \mathrm{~b}$. These results show that the catalytic performance can be kept stable after three circles, achieving $T_{10}=375-378{ }^{\circ} \mathrm{C}$, $T_{50}=468-475{ }^{\circ} \mathrm{C}, T_{90}=544-562{ }^{\circ} \mathrm{C}$ and around $97 \%$ of $\mathrm{CH}_{4}$ conversion at $600{ }^{\circ} \mathrm{C}$, indicating that the belt shape may be helpful to suppress catalyst aggregation. However, the stability is still poor as the nanobelts tend to aggregate when high temperature treatment is employed $\left(650^{\circ} \mathrm{C}\right)$ as shown in Figure 2e.
Moreover, the surface layers show higher crystallization after catalysis tests, as shown in Figure 2f, indicating that additional efforts to improve the thermal stability of these nanostructures is needed.

Although the calculated AE and DE can provide an explanation for the effect of morphology on catalysis performance, we further investigated the mechanism of full $\mathrm{CH}_{4}$ oxidation over $\mathrm{CuO}(001)$, which is informative for the further improvement and the design of new catalysts. Generally, $\mathrm{Cu}$ does not show strong magnetization in its neutral or fully oxidized forms, but spin-polarization for lowly coordinated $\mathrm{Cu}$ on the surface and radicals involved in $\mathrm{CH}_{4}$ oxidation deserves serious consideration. For instance, the difference in calculated adsorption energies with and without spin-polarization can be as high as $0.1-0.2 \mathrm{eV}$, with geometries showing slight differences too. Therefore, all energies and geometries shown below are based on spin-polarized calculations.

Starting from clean (001), $\mathrm{CH}_{4}$ is firstly adsorbed with $\mathrm{AE}=-0.86 \mathrm{eV}$, followed by a spontaneous dissociation with $\mathrm{CH}_{3}$ and $\mathrm{H}$ adsorbed on surface oxygen, as depicted in Figure $4 \mathrm{a}-\mathrm{c}$. Similar as discussed in an early publication [28], surface oxygen is often actively involved and may cleave $\mathrm{H}$ from $\mathrm{CH}_{x}$ to form $-\mathrm{OH}$ and $\mathrm{H}_{2} \mathrm{O}$, generating an oxygen vacancy $(\mathrm{OV})$, which can be filled with reactant $\mathrm{O}_{2}$, leading to its dissociation and further oxidizing $\mathrm{CH}_{x}$ intermediates, as shown in Figure $4 \mathrm{~d}-\mathrm{f}$. With oxygen transferring to bond with carbon, the hydrogen in $\mathrm{CH}_{x}$ can shift to surface oxygen again with an energy release of $3.66 \mathrm{eV}$ and $1.46 \mathrm{eV}$, indicating that such a shift is highly favorable, as shown in Figure $4 \mathrm{~g}-\mathrm{i}$. Again, an $\mathrm{OV}$ is generated and refilled by $\mathrm{O}_{2}$ when $\mathrm{H}_{2} \mathrm{O}$ is released, and simi-
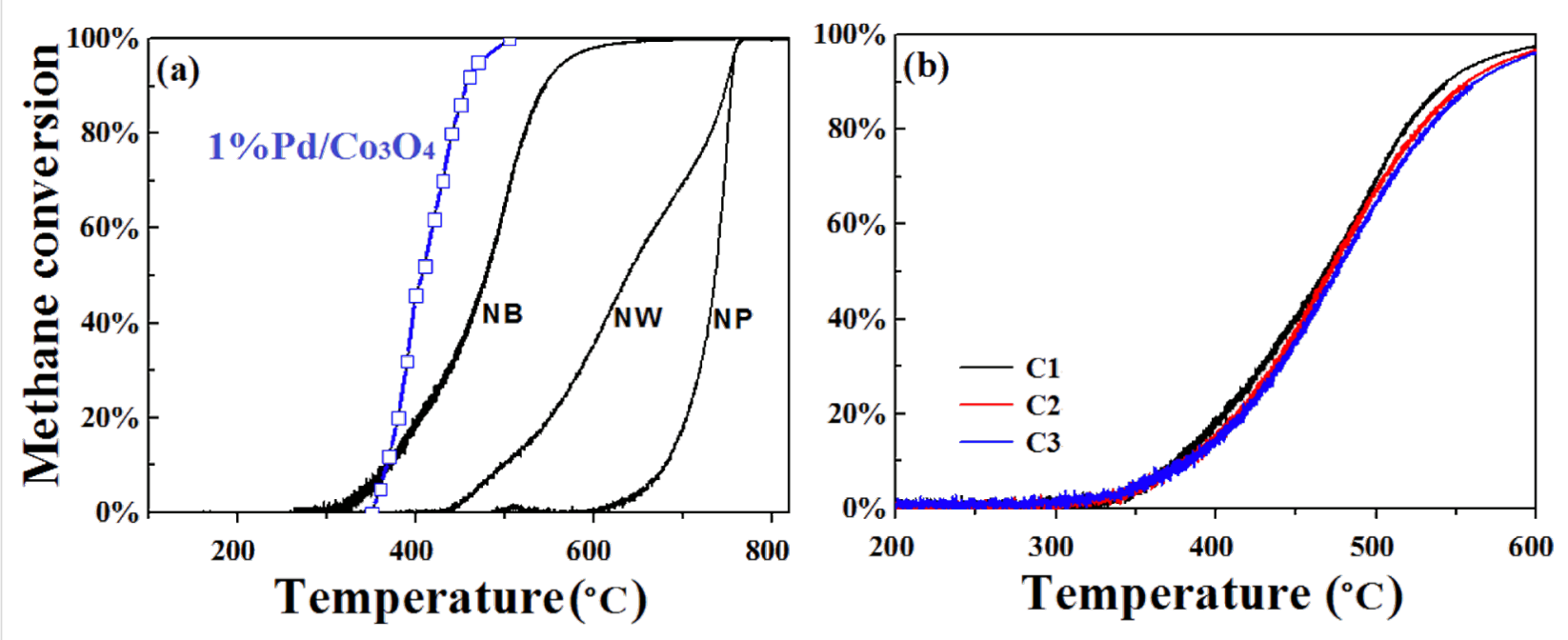

Figure 3: $\mathrm{CH}_{4}$ conversion against the temperature. (a) Heating profile $\left(T_{\max }=850{ }^{\circ} \mathrm{C}\right)$ for $\mathrm{NBs}, \mathrm{NWs}$ and $\mathrm{NPs}$, with $1 \% \mathrm{Pd} / \mathrm{Co}_{3} \mathrm{O}_{4}$ as a reference (b) Heating profile $\left(T_{\max }=600^{\circ} \mathrm{C}\right)$ for NBs tested for three cycles, labelled as $\mathrm{C} 1, \mathrm{C} 2$ and $\mathrm{C} 3$. 


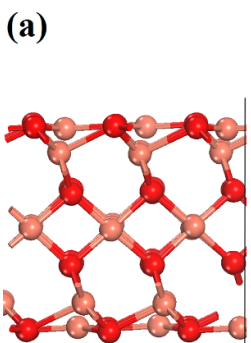

(g) (b) 8

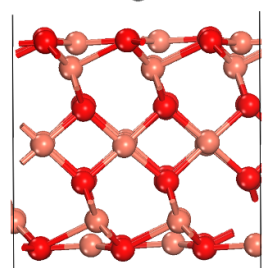

(c)

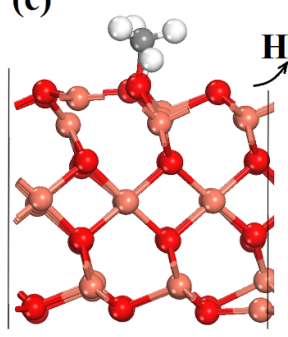

(d)

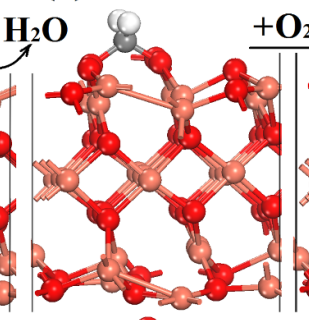

(e)

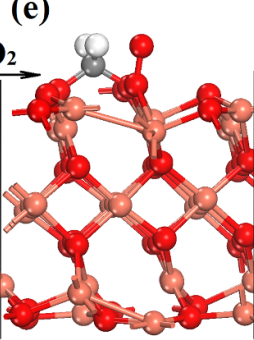

(k) (f)

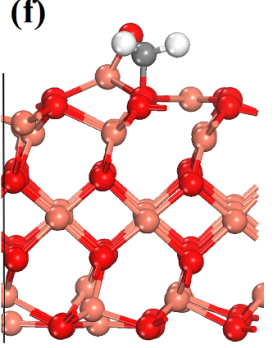

(I)
(I) 000

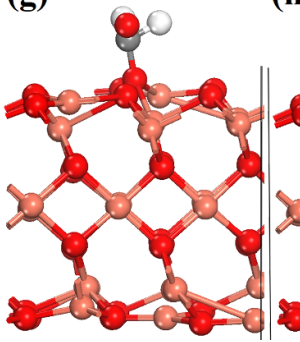

(h) (i)

(h) (i) (j)
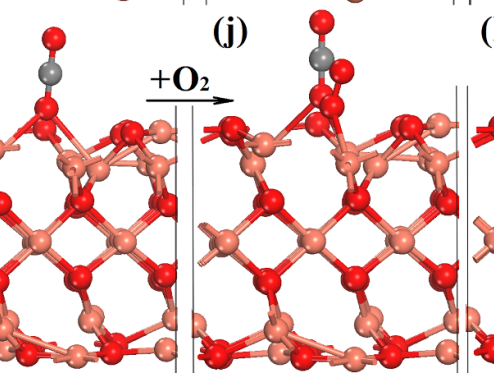

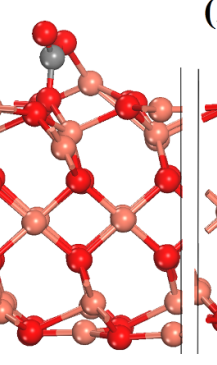

Figure 4: $\mathrm{CH}_{4}$ oxidation mechanism by computational calculations. (a) Clean (001); (b) $\mathrm{CH}_{4}$ physical adsorption; (c) $\mathrm{CH}_{4}$ dissociative adsorption; (d) $\mathrm{CH}_{2}{ }^{*}$ with oxygen vacancy $\left(\mathrm{OV}\right.$ ) presented; (e) $\mathrm{CH}_{2}{ }^{*}$ with $\mathrm{O}_{2}$ adsorbed; (f) $\mathrm{CH}_{2}{ }^{*}$ rotating and interacting with $\mathrm{O}_{2}{ }^{*}$; (g) transition state (TS) state $\mathrm{COH}_{2}{ }^{*}$; (h) $\mathrm{CHO}^{*}+\mathrm{H}^{*}$; (i) $\mathrm{CO}^{*}$ with OV presented after releasing one $\mathrm{H}_{2} \mathrm{O}$; (j) $\mathrm{CO}^{*}$ with $\mathrm{O}_{2}$ adsorbed; (k) $\mathrm{TS}_{\text {for }} \mathrm{O}$ transfer to $\mathrm{CO}^{*}$; (l) $\mathrm{CO}_{2}$ physical adsorbed. $\mathrm{Cu}, \mathrm{O}, \mathrm{C}$ and $\mathrm{H}$ are shown as rose-carmine, red, grey and white spheres, respectively.

larly $\mathrm{O}_{2}$ is dissociated to release atomic oxygen after exceeding the small barrier of $0.47 \mathrm{eV}$, which can oxidize adsorbed $\mathrm{CO}$ to form $\mathrm{CO}_{2}$, as outlined in Figure $4 \mathrm{i}-1$.

The energy profile for the above full process is given in Figure 5 in units of eV, using the total energy of a clean (001) surface and free gas-phase $\mathrm{CH}_{4}$ and $\mathrm{O}_{2}$ as the reference. According to the results, the early oxidation to release the first $\mathrm{H}_{2} \mathrm{O}$ (oxygen is from the surface) is exothermic and generates an $\mathrm{OV}$ (see Figure 4c). This is followed by $\mathrm{O}_{2}$ dissociation which occurs over the vacancy with a maximum energy barrier of $0.91 \mathrm{eV}$. This is informative because it indicates that the key role of $\mathrm{OV}$ is to activate $\mathrm{O}_{2}$ and release a highly active oxygen atom, although a barrier of $0.91 \mathrm{eV}$ is found for $\mathrm{O}_{2}$ dissociation in the case of $\mathrm{CuO}(001)$, but the dehydrogenation from $\mathrm{CH}_{x}$ becomes exothermic, confirming the importance of surface oxygen and oxygen vacancies, as suggested by $\mathrm{Hu}$ et al. [22] and Jin et al. [28]. According to this understanding, the catalysis performance may be further improved by adding alloy elements or surface doping to reduce the barrier.

\section{Conclusion}

In summary, $\mathrm{Cu}(001)$ was identified as being the most promising among six low-index surfaces tested for $\mathrm{CH}_{4}$ oxidation based on the criteria of adsorption energy and dissociation energy. These calculations were experimentally examined with the use of $\mathrm{CuO}$ NBs comprised of predominantly (001) sur-

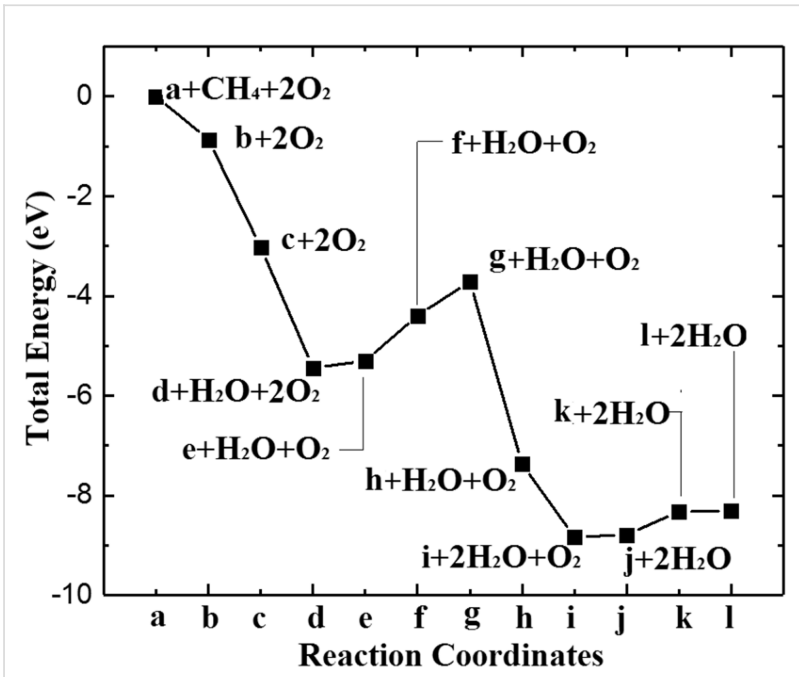

Figure 5: Energy profile for $\mathrm{CH}_{4}$ oxidation. The geometries are shown in Figure 4.

faces, which performed better than $\mathrm{CuO}$ NBs and NPs, achieving almost complete oxidation at a temperature of $600{ }^{\circ} \mathrm{C}$. $\mathrm{CuO}$ NBs, employed as low-cost catalysts, can be used without additional agents to disperse or support them. They can therefore be loaded with higher concentration in limited space or weight applications, making $\mathrm{CuO}$ NBs a promising replacement to expensive Pd-based catalysts. Additional efforts are needed to improve the thermal stability of such nano- 
structures as they tend to aggregate after high temperature treatment.

\section{Experimental \\ Synthesis of $\mathrm{CuO}$ nanowires and nanobelts}

For a typical sample, $1 \mathrm{~g}$ of $\mathrm{Cu}\left(\mathrm{NO}_{3}\right)_{2}$ was dissolved in $100 \mathrm{~mL}$ distilled water and $30 \mathrm{~mL}$ ammonia solution $\left(\mathrm{NH}_{3} \cdot \mathrm{H}_{2} \mathrm{O}\right.$, $0.15 \mathrm{~mol} / \mathrm{L}$ ) was added under vigorous stirring. Then, $\mathrm{NaOH}$ solution $(1 \mathrm{~mol} / \mathrm{L})$ was added dropwise to the above solution and the $\mathrm{pH}$ value was adjusted to $9-10$. The resulting blue $\mathrm{Cu}(\mathrm{OH})_{2}$ precipitate was filtered and washed several times with distilled water to obtain a solid product. $\mathrm{CuO}$ NWs were prepared by heating one part of the as-obtained solid product at $130{ }^{\circ} \mathrm{C}$ for $10 \mathrm{~h}$ in an oven. The other part was dissolved in $50 \mathrm{~mL}$ distilled water, then transferred to an autoclave and hydrothermally treated at $130^{\circ} \mathrm{C}$ for $10 \mathrm{~h}$. The black solid product was washed with deionized water and dried at $60{ }^{\circ} \mathrm{C}$ overnight to get $\mathrm{CuO} \mathrm{NBs}$ [23].

\section{Methane catalytic oxidation test}

Methane catalytic oxidation experiments were carried out in a fixed-bed reactor (U-shaped quartz tube) with an inner diameter of $6 \mathrm{~mm}$ at atmospheric pressure. $35 \mathrm{mg}$ of the catalysts was loaded into the reactor and supported by quartz wool. A mixed reaction gas containing $0.6 \mathrm{vol} \% \mathrm{CH}_{4}, 19.6$ vol \% $\mathrm{O}_{2}$, $0.15 \% \mathrm{CO}_{2}$ and balance $\mathrm{N}_{2}$ was flowed through the catalyst bed at a flow rate of $20 \mathrm{~mL} \mathrm{~min}{ }^{-1}$, corresponding to a gas hourly space velocity of $34,000 \mathrm{~mL} \mathrm{~h}^{-1} \mathrm{~g}^{-1}$. Prior to the catalytic tests, the catalyst was pretreated under the reaction atmosphere for $60 \mathrm{~min}$ at $250{ }^{\circ} \mathrm{C}$ and then cooled down to $150^{\circ} \mathrm{C}$. Once the temperature was stable at $150{ }^{\circ} \mathrm{C}, \mathrm{CH}_{4}$ oxidation catalytic performance was evaluated by heating the catalyst bed at $10{ }^{\circ} \mathrm{C} \min ^{-1}$ to 850 or $600{ }^{\circ} \mathrm{C}$. The composition of the effluent gases were monitored on-line using a quadrupole mass spectrometer (Hiden MS HPR20) with a secondary electron multiplier detector. Methane conversion was defined as: (influent concentration of $\mathrm{CH}_{4}$ - effluent concentration of $\mathrm{CH}_{4}$ )/influent concentration of $\mathrm{CH}_{4} \times 100 \%$.

\section{Theoretical calculations}

Spin-polarized DFT calculations were performed under the generalized gradient approximation (GGA) [29] together with the functional by Perdew, Burke, and Ernzerhof [30], which was embedded in the Vienna Ab-Initio Simulation Package [31]. The calculation was carried out with a kinetic cutoff energy of $380 \mathrm{eV}$, with the use of the projector augmented wave (PAW) method. The k-space was sampled by the gamma point based on our tests. The k-point and cutoff energy were tested with higher computational settings, as $3 \times 3 \times 1$ and $450 \mathrm{eV}$, leading to the difference of less than $0.1 \mathrm{eV}$ in terms of the adsorption energies. The van der Waals (vdW) interaction was considered with the use of the DFT-D3 method, as developed by Grimme and Jónsson [32,33]. The $\mathrm{CuO}$ surfaces were modelled by $2 \times 2$ supercells, shown as slabs with thicknesses in the range of 10-14 $\AA$, depending on the surface orientation, and a vacuum space of $12 \AA$ was applied over the surface. The transition state (TS) was identified through the dimer method [33], for which the searching is carried out by a series of intermediate states generated among the reaction path towards the formation of the product and further optimized with one static degree of freedom (in our case, one bond length associated with the change from reactant to product). Based on our tests, both spin-polarization and vdW corrections are necessary, especially for the calculation of intermediate radicals involved in $\mathrm{CH}_{4}$ oxidation (e.g., $\mathrm{CH}_{2} *, \mathrm{CH}^{*}$ and $\mathrm{O}^{*}$ ).

During the quick screening of surfaces for $\mathrm{CH}_{4}$ adsorption, the adsorption energy (AE) and dissociation energy (DE) from physical adsorption to dissociative adsorption have been employed, which are defined as follows.

$\mathrm{AE}=E\left(\mathrm{CH}_{4}{ }^{*}\right)-E($ surface $)-E\left(\mathrm{CH}_{4}\right.$-gas phase $)$

$\mathrm{DE}=E\left(\mathrm{CH}_{3} *-\mathrm{H}^{*}\right)-E\left(\mathrm{CH}_{4} *\right)$

To understand the catalysis mechanism, full methane oxidation, $\mathrm{CH}_{4}+2 \mathrm{O}_{2} \rightarrow \mathrm{CO}_{2}+\mathrm{H}_{2} \mathrm{O}$, has been investigated in which the total energy of $\mathrm{CH}_{4}, \mathrm{CO}_{2}$ and $\mathrm{H}_{2} \mathrm{O}$ was calculated as $-24.02 \mathrm{eV},-23.64 \mathrm{eV}$ and $-14.23 \mathrm{eV}$, respectively. The total energy of $\mathrm{O}_{2}$ was derived from $\mathrm{H}_{2} \mathrm{O}$ and $\mathrm{H}_{2}$, giving $-9.97 \mathrm{eV}$. Based on the above, the reaction energy for $\mathrm{CH}_{4}$ oxidation was calculated as $-8.14 \mathrm{eV}$, which is close to the experimental data $(\Delta H=-8.31 \mathrm{eV}$ at room temperature).

\section{Supporting Information}

\section{Supporting Information File 1}

$\mathrm{X}$-ray diffraction profile.

[https://www.beilstein-journals.org/bjnano/content/ supplementary/2190-4286-9-235-S1.pdf]

\section{Acknowledgements}

This work is supported by National Natural Science Foundation of China (Grant Nos. 51302231, 11572057), the Australian Research Council through Discover Project (DP130100268, DP140100193, DP150100056, CS \& ZC) and Future Fellowship (FT130100076, CS) and CSIRO Energy. The authors thank the National Computational Infrastructure (NCI) for providing the computational resources. We acknowledge the use of facilities within the Monash Centre for Electron Microscopy and ARC funding (LE110100223). 


\section{ORCID ${ }^{\circledR}$ iDs}

Qingquan Kong - https://orcid.org/0000-0002-2618-5168 Chenghua Sun - https://orcid.org/0000-0001-7654-669X

\section{References}

1. Demoulin, O.; Navez, M.; Gaigneaux, E. M.; Ruiz, P.; Mamede, A.-S.; Granger, P.; Payen, E. Phys. Chem. Chem. Phys. 2003, 5, 4394-4401. doi:10.1039/B305817B

2. Cullis, C. F.; Willatt, B. M. J. Catal. 1983, 83, 267-285. doi:10.1016/0021-9517(83)90054-4

3. Choudhary, T. V.; Banerjee, S.; Choudhary, V. R. Appl. Catal., A 2002, 234, 1-23. doi:10.1016/S0926-860X(02)00231-4

4. Haynes, W. M. CRC Handbook of Chemistry and Physics, 96th ed.; CRC Press, 2014.

5. Ciuparu, D.; Lyubovsky, M. R.; Altman, E.; Pfefferle, L. D.; Datye, A. Catal. Rev.: Sci. Eng. 2002, 44, 593-649. doi:10.1081/CR-120015482

6. Cargnello, M.; Delgado Jaén, J. J.; Hernandez Garrido, J. C.; Bakhmutsky, K.; Montini, T.; Calvino Gámez, J. J.; Gorte, R. J.; Fornasiero, P. Science 2012, 337, 713-717. doi:10.1126/science. 1222887

7. Farrauto, R. J. Science 2012, 337, 659-660. doi:10.1126/science. 1226310

8. Chen, J.; Arandiyan, H.; Gao, X.; Li, J. Catal. Surv. Asia 2015, 19, 140-171. doi:10.1007/s10563-015-9191-5

9. Farrauto, R. J.; Hobson, M. C.; Kennelly, T.; Waterman, E. M. Appl. Catal., A 1992, 81, 227-237. doi:10.1016/0926-860X(92)80095-T

10. Gélin, P.; Primet, M. Appl. Catal., B 2002, 39, 1-37. doi:10.1016/S0926-3373(02)00076-0

11. Abbasi, R.; Huang, G.; Istratescu, G. M.; Wu, L.; Hayes, R. E. Can. J. Chem. Eng. 2015, 93, 1474-1482. doi:10.1002/cjce.22229

12. Nilsson, J.; Carlsson, P.-A.; Fouladvand, S.; Martin, N. M.; Gustafson, J.; Newton, M. A.; Lundgren, E.; Grönbeck, H.; Skoglundh, M. ACS Catal. 2015, 5, 2481-2489. doi:10.1021/cs502036d

13. Kozlov, S. M.; Neyman, K. M. J. Catal. 2016, 337, 111-121. doi:10.1016/j.jcat.2016.02.010

14. Mayernick, A. D.; Janik, M. J. J. Catal. 2011, 278, 16-25. doi:10.1016/j.jcat.2010.11.006

15. Pi, D.; Li, W. Z.; Lin, Q. Z.; Huang, Q. F.; Hu, H. Q.; Shao, C. Y. Energy Technol. 2016, 4, 943-949. doi:10.1002/ente.201600006

16. Bychkov, V. Y.; Tulenin, Y. P.; Slinko, M. M.; Khudorozhkov, A. K.; Bukhtiyarov, V. I.; Sokolov, S.; Korchak, V. N. Catal. Commun. 2016, 77, 103-107. doi:10.1016/j.catcom.2016.01.028

17. Hayes, R. E.; Kolaczkowski, S. T.; Li, P. K. C.; Awdry, S. Chem. Eng. Sci. 2001, 56, 4815-4835. doi:10.1016/S0009-2509(01)00131-2

18. Ahmadi, T. S.; Wang, Z. L.; Green, T. C.; Henglein, A.; El-Sayed, M. A. Science 1996, 272, 1924-1925. doi:10.1126/science.272.5270.1924

19. Xie, X.; Li, Y.; Liu, Z.-Q.; Haruta, M.; Shen, W. Nature 2009, 458, 746-749. doi:10.1038/nature07877

20. Yang, H. G.; Sun, C. H.; Qiao, S. Z.; Zou, J.; Liu, G.; Campbell Smith, S.; Cheng, H. M.; Lu, G. Q. Nature 2008, 453, 638-641. doi:10.1038/nature06964

21. Su, D.; Xie, X.; Dou, S.; Wang, G. Sci. Rep. 2014, 4, 5753. doi:10.1038/srep05753

22. Hu, W.; Lan, J.; Guo, Y.; Cao, X.-M.; Hu, P. ACS Catal. 2016, 6, 5508-5519. doi:10.1021/acscatal.6b01080

23. Du, G. H.; Van Tendeloo, G. Chem. Phys. Lett. 2004, 393, 64-69. doi:10.1016/j.cplett.2004.06.017
24. Huang, H.; Yu, Q.; Ye, Y.; Wang, P.; Zhang, L.; Gao, M.; Peng, X.; Ye, Z. CrystEngComm 2012, 14, 7294-7300. doi:10.1039/c2ce25873k

25. Dey, K. K.; Kumar, A.; Shanker, R.; Dhawan, A.; Wan, M.; Yadav, R. R.; Srivastava, A. K. RSC Adv. 2012, 2, 1387-1403. doi:10.1039/C1RA00710F

26. Zhang, Q.; Zhang, K.; Xu, D.; Yang, G.; Huang, H.; Nie, F.; Liu, C.; Yang, S. Prog. Mater. Sci. 2014, 60, 208-337. doi:10.1016/j.pmatsci.2013.09.003

27. Ercolino, G.; Grzybek, G.; Stelmachowski, P.; Specchia, S.; Kotarba, A.; Specchia, V. Catal. Today 2015, 257, 66-71. doi:10.1016/j.cattod.2015.03.006

28. Jin, Y.; Sun, C.; Su, S. Phys. Chem. Chem. Phys. 2015, 17, 16277-16284. doi:10.1039/C5CP00761E

29. Kohn, W.; Sham, L. J. Phys. Rev. 1965, 140, A1133-A1138. doi:10.1103/PhysRev.140.A1133

30. Perdew, J. P.; Burke, K.; Ernzerhof, M. Phys. Rev. Lett. 1996, 77, 3865-3868. doi:10.1103/PhysRevLett.77.3865

31. Kresse, G.; Joubert, D. Phys. Rev. B 1999, 59, 1758-1775. doi:10.1103/PhysRevB.59.1758

32. Goerigk, L.; Grimme, S. J. Chem. Theory Comput. 2010, 6, 107-126 doi:10.1021/ct900489g

33. Henkelman, G.; Jónsson, H. J. Chem. Phys. 1999, 111, 7010-7022. doi:10.1063/1.480097

\section{License and Terms}

This is an Open Access article under the terms of the Creative Commons Attribution License (http://creativecommons.org/licenses/by/4.0). Please note that the reuse, redistribution and reproduction in particular requires that the authors and source are credited.

The license is subject to the Beilstein Journal of

Nanotechnology terms and conditions:

(https://www.beilstein-journals.org/bjnano)

The definitive version of this article is the electronic one which can be found at: doi:10.3762/bjnano.9.235 